\section{Evaluation of Blood Parameters Alteration Following Low-dose Radiation Induced by Myocardial Perfusion Imaging}

\author{
Alavi M. S.,2, Okhovat M. A. ${ }^{3}$, Atefi M.,2*, Khajeh Rahimi \\ F. $^{2}$, Mortazavi S. ${ }^{2}$, Ebadi F. ${ }^{2}$
}

\begin{abstract}
Introduction: With increasing the usage of myocardial perfusion imaging (MPI) for the diagnosis of ischemic heart disease, we aimed to evaluate the side effects of low-dose radiation induced by this technique on blood elements, especially proteins and liver function factors.
\end{abstract}

Material and Methods: 40 eligible patients (Mean age: $54.62 \pm 10.35,22$ female and 18 male), who had referred to the nuclear medicine department for MPI from May till August 2014, were enrolled in the study. A blood sample was taken from each patient just before and 24 hours after the injection of $740 \mathrm{Mbq}$ of Tecnetium-99m Methoxy isobutyl isonitrile (99mTc-MIBI) in the rest phase of the MPI in a reference medical laboratory; blood tests included total protein (TP), albumin (Alb), globulin (Glo), aspartate aminotransferase (AST), alanine transaminase (ALT), alkaline phosphatase (ALP), direct bilirubin (D.Bili), total bilirubin (T.Bili), serum iron (SI), total iron bounding capacity (TIBC), Albumin globulin ratioA/G ratio), and complete blood count (CBC).

Results: Injection of $740 \mathrm{Mbq} 99 \mathrm{mTc}-\mathrm{MIBI}$ caused a significant increase in serum levels of AST $(p=0.001), \operatorname{ALT}(p=0.001)$, SI $(p=0.030), \operatorname{TIBC}(p=0.003)$ and A/G Ratio $(p=0.020)$. However, following radiotracer injection, a significant decrease was noted in the serum levels of TP $(p=0.002), \operatorname{Alb}(p=0.014)$, Glo $(p=0.002)$, ALP $(\mathrm{p}=0.001)$, D.Bili $(\mathrm{p}=0.003)$ and T.Bili $(\mathrm{p}=0.000)$.

Conclusion: Due to increased usage of MPI, our data highlights the importance of monitoring the clinical and paraclinical effects of the procedure on vital organs and physiological pathways to reduce their adverse effects.

\section{Keywords}

Low-dose Radiation, Blood Biomarkers, Myocardial Perfusion Imaging

\section{Introduction}

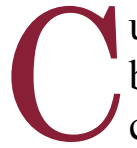
urrently, radioactive tracers play a significant role in the field of biological sciences, particularly nuclear medicine [1]. Radionuclides are used in nuclear medicine in a variety of ways. Two risk groups are identified following the administration of radiopharmaceutical: the patient and the groups of individuals exposed to the patient. According to a recent report by the National Council on Radiation Protection and Measurements, the number of people exposed to radiation from medical imaging has increased by six-folds in the past three decades
${ }^{1}$ Ionizing and Non-Ionizing Radiation Protection

Research Center, School

of Paramedical Sci-

ences, Shiraz University

of Medical Sciences,

Shiraz, Iran

${ }^{2}$ Nuclear Medicine

Department, Faculty of

Medicine, Shiraz Univer-

sity of Medical Sciences,

Shiraz, Iran

${ }^{3}$ Diagnostic Laboratory

Sciences and Technol-

ogy Research Center,

School of Paramedical

Sciences, Shiraz Univer-

sity of Medical Sciences,

Shiraz, Iran

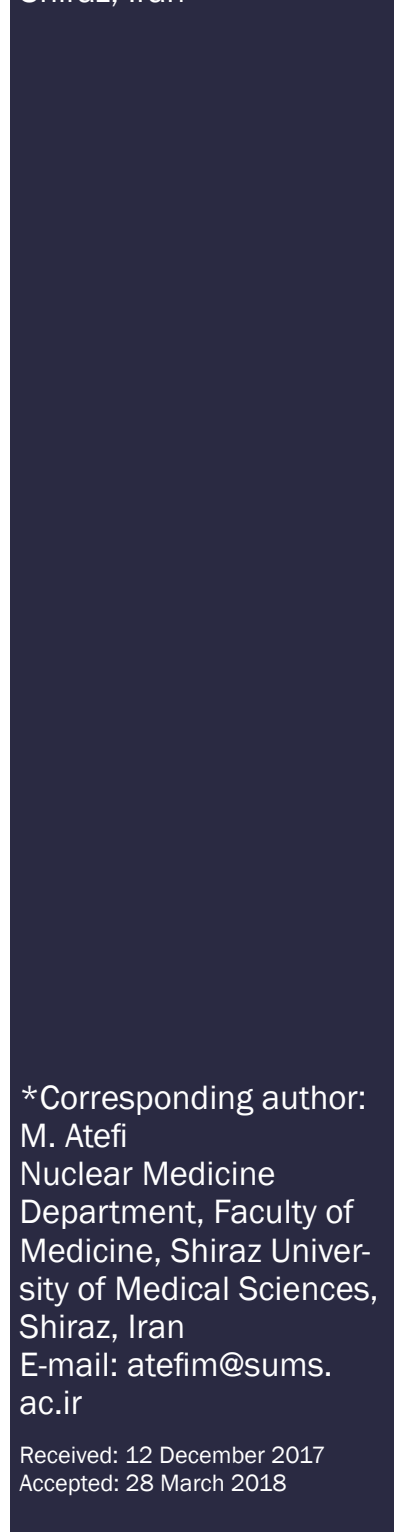


and at present approximately $40 \%$ of medical radiation exposure (excluding radiotherapy) comes from cardiovascular imaging and image-guided interventions [2]. Patients usually receive low-dose radiation following the administration of diagnostic radiopharmaceutical. In most diagnostic procedures, radiation dose is less than $20 \mathrm{mSv}$. Some studies have shown that many patients are being exposed to multiple doses of radiation which can lead to high cumulative dose, therefore, it is necessary to take a more cautious approach regarding the patient's absorbed dosage [3].

Myocardial Perfusion Imaging (MPI) is one of the most common techniques which is used in the field of nuclear medicine. Technetium-99m compounds are used to image heart muscle perfusion and emits photons with energies $140 \mathrm{KeV}$ [4] It is usually performed by Technetium-99m methoxy isobutyl isonitrile (99mTc-MIBI), in two separate stress and rest phases [6]. The bio-distribution of $99 \mathrm{mTc}-\mathrm{MI}-$ $\mathrm{BI}$ is characterized by a rapid blood clearance and consequently early myocardial uptake. The initial intense hepatic activity is cleared into the gall bladder after $1 \mathrm{~h}$ and the best target to non-target ratio is observed at $60-90 \mathrm{~min}$ post injection. Absorbed radiation dose calculation demonstrates that thyroid is the critical target organ $(230 \mathrm{mRad} / \mathrm{mCi}$ at rest), apparently because of $99 \mathrm{mTc}$-pertechnetate generated in vivo [5]. Recently, scientists focused on the effects of exposure on liver function in the nuclear medicine department [6-11].

The aim of this study was to evaluate the early fluctuations of some blood proteins and liver function tests following the rest phase of the MPI.

\section{Material and Methods}

According to Helsinki Declaration, forty patients were enrolled in this randomized controlled trial study. All these patients were referred to nuclear medicine department of Namazi Hospital for MPI from May 2014 for
4 months. Amongst them, 22 were female and 18 were male with age range of $36-72$ years old. The inclusion criterion for this study was normal hepatic function tests without any history of hematologic disorders.

The exclusion criteria were kidney disorders, hepatic or hematological disorders and abnormal liver function tests. All experiments with human subjects were approved by the Ethics Committee of Shiraz University of Medical Sciences. Verbal and written informed consent was taken from each patient.

MPI was performed at rest phase of the study on the first day followed by stress phase on the second day. In each phase, $740 \mathrm{MBq}$ (20 mci) 99mTc-MIBI was injected intravenously. From each patient, 4 milliliter of blood samples were collected before as well as 24 hours after injection of $99 \mathrm{mTc}-\mathrm{MIBI}$ in the rest phase of the study. Blood samples were taken before stress phase of the study to exclude the potential effects of the stressors on the results. All kits are from Audit Company.

Laboratory tests including Total Protein(TP), Albumin(Alb), Globulin(Glo), Aspartate Aminotransferase (AST), Alanine Aminotransferase (ALT), Alkaline Phosphatase (ALP), Direct Bilirubin (D.Bili), Total Bilirubin (T.Bili), Serum Iron (SI), Total Iron Bounding Capacity (TIBC), Albumin Globulin ratio(A/G Ratio) and complete blood Count (CBC) were measured in a reference medical laboratory. Each test was duplicated to confirm the reproducibility of the results.

\section{Statistical Analysis}

The gathered data were analyzed by SPSS V.20 software. A paired-sample t-test was used to determine whether there was a statistically significant mean difference between the mentioned blood parameters before and after injection of $99 \mathrm{mTc}-\mathrm{MIBI}$. Data are mean \pm standard deviation, unless otherwise stated. In all cases, $\mathrm{p}<0.05$ was considered statistically significant. 


\section{Results}

Forty patients, 18 males and 22 females participated in the study. Demographic data are shown in Table 1.

Blood levels measurement of TP, Alb, Glo, AST, ALT, ALP, D.Bili, T.Bili, SI, TIBC and A/G Ratio are shown in Table 2.

Based on the results, AST, ALT, SI, TIBC and $A / G$ Ratio levels increased significantly in patients' blood samples 24 hours after injection of $740 \mathrm{Mbq} 99 \mathrm{mTc}-\mathrm{MIBI}$ in comparison to pre-injection levels; whereas, TP Alb, Glo, ALP, D.Bili and T.Bili significantly decreased when compared to pre-injection levels. CBC levels exhibited no significant changes. There

Table 1: Demographic data of patients.

\begin{tabular}{ccc} 
Items & Mean \pm SD & Minimum-Maximum \\
\hline Age (years) & $54.62 \pm 10.35$ & $36-72$ \\
\hline \multirow{2}{*}{ Sex $(\%)$} & Male & $18(45 \%)$ \\
\cline { 2 - 3 } & Female & $22(55 \%)$
\end{tabular}

were no correlations between biochemical parameter changes and the patient's age or sex.

\section{Discussion and Conclusion}

Recent exposure to low-dose radiation has become an interesting subject for many scientists[12-16]. The use of diagnostic imaging particularly MPI which has low-dose ionizing radiation has increased in recent years; this has created a renewed interest in the evaluation of early adverse effects of low-dose radiation exposure for patients.

According to analyzed data, the mean value of statistical variables of TP, Alb, Glo, AST, ALT, ALP, D.Bili, T.Bili, SI, TIBC and A/G Ratio were statistically significant $(\mathrm{P}<0.05)$. While the injection of $99 \mathrm{mTc}$ MIBI showed no statistical significant changes on the $\mathrm{CBC}$ level $(\mathrm{P}$ value $>0.05)$. Sony et al. reported that by increasing the radiation dose in the animal model $\mathrm{P}$ decreased [17]. These data are consistent with data obtained in our study. Nwozo et al. showed that irradiation of $6 \mathrm{~Gy}$ $\mathrm{y}$-radiation to male Wistar rats caused an increase in serum concentrations levels of ALT

Table 2: The results of laboratory analysis. 1 represents before and 2 represent after radiotracer injection.

\begin{tabular}{ccccc} 
Paired-Samples & \multicolumn{3}{c}{ Paired Differences } & \multirow{2}{*}{ P- Value } \\
\cline { 2 - 4 } Sig. (2-tailed) & Mean & SD & Std. Error Mean & \\
\hline TP 1 - TP 2 & 0.2450 & 0.4585 & 0.0725 & 0.002 \\
\hline Alb 1 - Alb 2 & 0.1050 & 0.2572 & 0.0407 & 0.014 \\
\hline Glo 1 - Glo 2 & 0.1475 & 0.2764 & 0.0437 & 0.002 \\
\hline AST 1 - AST 2 & -9.5250 & 17.4694 & 2.7621 & 0.001 \\
\hline ALT 1 - ALT 2 & -9.1250 & 16.8632 & 2.6663 & 0.001 \\
\hline ALP 1 - ALP 2 & 19.0250 & 34.9105 & 5.5198 & 0.001 \\
\hline D.Bili 1 - D.Bili 2 & 0.0350 & 0.0700 & 0.0111 & 0.003 \\
\hline T.Bili 1 - T.Bili 2 & 0.2075 & 0.3092 & 0.0489 & 0.000 \\
\hline SI1 - SI2 & -13.4250 & 37.6413 & 5.9516 & 0.030 \\
\hline TIBC 1 - TIBC 2 & -20.9500 & 42.0524 & 6.6491 & 0.003 \\
\hline A/G 1 - A/G 2 & -0.0450 & 0.1176 & 0.0186 & 0.020
\end{tabular}


and AST [18]. In addition, Li et al. proved that the use of ALT was a significant predictive factors for radiation-induced liver injury [19]. In our study, we revealed that radiation dose could cause an increase in the level of ALT and AST. Chi C. et al. reported that following exposure to Co $\gamma$-ray albumin serum level decreased while globulin serum level increased [20]. Our study showed a decrease in A/G ratio after exposure to low-dose radiation which was in contradiction to pervious study. In our study, we observed a statistically significant decrease in T.Bili and D.Bili serum levels after the injection of $99 \mathrm{mTc}$ MIBI. Similarly, many other studies have shown that after exposure to low-dose radiation, serum levels of D.Bili and T.Bili decreased as well as uur results [21-23]. Our results showed that 99mTcMIBI significantly increased SI and TIBC serum levels. These results are relevant with previous studies [24-25]. The study also found that a significant difference exists in the $\mathrm{A} / \mathrm{G}$ ratio before and after injection of $99 \mathrm{mTcMIBI}$. As $\mathrm{A} / \mathrm{G}$ ratio in serum increased after injection of 99mTc-MIBI; however, we observed that Alb and Glo amounts decreased. Our study also exhibited a statistically significant decrease in $\mathrm{TP}$ and Alp serum levels as well. CBC was also checked before and after the injection of the radio tracer and no statistical differences were observed.

We evaluated the effects of radiation on the resting phase of the procedure to eliminate the possible effects of the stressors. Radiationinduced effects of MPI would be much higher if the radiation caused by stress phase was added.

In our study, statistical biomarker changes following low-dose radiation was confirmed. This might cause adverse effects on vital organs especially liver or promote the deterioration of physiological functions. Further studies on the long-term effects of low-dose radiation on the blood biomarkers are suggested.

\section{Acknowledgment}

This study was supported by a research grant from Shiraz University of Medical Sciences, Iran. The authors would like to thank Mr. H. Argasi at the Research Consultation Center (RCC) of Shiraz University of Medical Sciences for his invaluable assistance in editing this article.

\section{Conflict of Interest}

The authors report no declarations of interest.

\section{References}

1. Alavi MS, Azarpira N, Mojallal M. Incidental finding of bilateral papillary thyroid carcinoma in a patient with primary hyperparathyroidism. Hell J Nucl Med. 2010;13:56-8. PubMed PMID: 20411173.

2. Lee WH, Nguyen PK, Fleischmann D, Wu JC. DNA damage-associated biomarkers in studying individual sensitivity to low-dose radiation from cardiovascular imaging. Eur Heart J. 2016;37:3075-80. doi: 10.1093/eurheartj/ ehw206. PubMed PMID: 27272147.

3. Fazel R, Shaw LJ. Radiation exposure from radionuclide myocardial perfusion imaging: concerns and solutionsv. J Nucl Cardiol. 2011;18:562-5. doi: 10.1007/s12350-0119403-y. PubMed PMID: 21638151.

4. Helal N. Patient organs dose calculations in nuclear medicine. Int $J$ Res Rev Appl Sci. 2012;11:153-61.

5. Savi A, Gerundini P, Zoli P, Maffioli L, Compierchio A, Colombo $F$, et al. Biodistribution of Tc-99m methoxy-isobutyl-isonitrile (MIBI) in humans. Eur J Nucl Med. 1989;15:597-600. PubMed PMID: 2598955.

6. Savelli G, Basile P, Andreoli M, Pizzocaro C, Kaiser SR, Zaniboni A. ImmunoPET in Neoplasms of Gastrointestinal Tract, Liver and Pancreas in the XXIst Century: Bridging the Gap Between Diagnosis and Therapy. Rev Recent Clin Trials. 2015;10:146-54. PubMed PMID: 25800243.

7. Gates VL, Singh N, Lewandowski RJ, Spies S, 
Salem R. Intraarterial hepatic SPECT/CT imaging using 99mTc-macroaggregated albumin in preparation for radioembolization. $J \mathrm{NuCl}$ Med. 2015;56:1157-62.

8. Bertagna F, Piccardo A, Dib B, Bertoli M, Fracassi $F$, Bosio G, et al. Multicentre study of 18F-FDG-PET/CT prostate incidental uptake. Japanese journal of radiology. 2015;33:53846.

9. Legou F, Chiaradia M, Baranes L, Pigneur F, Zegai $B$, Djabbari $M$, et al. Imaging strategies before beginning treatment of colorectal liver metastases. Diagnostic and interventional imaging. 2014;95:505-12.

10.Tan TH, Lee BN, Hassan SZA. Diagnostic value of $68 \mathrm{Ga}$-DOTATATE PET/CT in liver metastases of neuroendocrine tumours of unknown origin. Nucl Med Mol Imaging (2010). 2014;48:212-5.

11.Sen $H$, Tan $Y Z$, Binnetoglu E, Asik M, Günes F, Erbag G, et al. Evaluation of liver perfusion in diabetic patients using 99mTc-sestamibiErhebung der Leberperfusion mittels 99mTcSestamibi bei Patienten mit Diabetes mellitus. Wiener klinische Wochenschrift. 2015;127:1923.

12. Siegel JA, Welsh JS. Does Imaging Technology Cause Cancer? Debunking the Linear NoThreshold Model of Radiation Carcinogenesis. Technol Cancer Res Treat. 2016;15:249-56. doi: $10.1177 / 1533034615578011$. PubMed PMID: 25824269.

13. Shahid S, Mahmood N, Chaudhry MN, Sheikh $\mathrm{S}$, Ahmad N. Mutations of the human interferon alpha-2b (hIFN- $\alpha 2 b$ ) gene in occupationally protracted low dose radiation exposed personnel. Cytokine. 2015;73:181-9.

14. Brooks AL, Dauer LT. Advances in radiation biology: effect on nuclear medicine. Semin Nucl Med. 2014;44:179-86. doi: 10.1053/j. semnuclmed.2014.03.004. PubMed PMID: 24832582.

15.Alavi M, Taeb S, Okhovat M, Atefi M, Negahdari F. Look Different: Effect of Radiation Hormesis on the Survival Rate of Immunosuppressed Mice. Journal of biomedical physics
\& engineering. 2016;6:139.-146.

16. Bolus NE. Basic review of radiation biology and terminology. J Nucl Med Technol. 2001;29:67-73. PubMed PMID: 11376098.

17.Soni S, Agrawal P, Kumar N, Mittal G, Nishad DK, Chaudhury NK, et al. Salivary biochemical markers as potential acute toxicity parameters for acute radiation injury: A study on small experimental animals. Hum Exp Toxicol. 2016;35:221-8. doi: 10.1177/0960327115579433. PubMed PMID: 25813962.

18. Nwozo S, Okameme P, Oyinloye B. Potential of Piper guineense and Aframomum longiscapum to reduce radiation induced hepatic damage in male Wistar rats. Radiats Biol Radioecol. 2012;52:363-9.

19.Li G, Wang J, Hu W, Zhang Z. Radiation-induced liver injury in three-dimensional conformal radiation therapy (3D-CRT) for postoperative or locoregional recurrent gastric cancer: risk factors and dose limitations. PLOS One. 2015;10:e0136288.

20.Chi C, Tian R, Liu H, Wang H, Wei J, Guo J, et al. Follow-up study of abnormal biological indicators and gene expression in the peripheral blood of three accidentally exposed persons. $J$ Radiat Res (Tokyo). 2013;54:840-51.

21.Barshishat-Kupper M, Tipton AJ, McCart EA, McCue J, Mueller GP, Day RM. Effect of ionizing radiation on liver protein oxidation and metabolic function in C57BL/6J mice. Int $J$ Radiat Biol. 2014;90:1169-78.

22. Brinkhaus G, Lock JF, Malinowski M, Denecke T, Neuhaus P, Hamm B, et al. CT-guided highdose-rate brachytherapy of liver tumours does not impair hepatic function and shows high overall safety and favourable survival rates. Ann Surg Oncol. 2014;21:4284-92.

23. Yu Jl, Park HC, Lim DH, Paik SW. Do Biliary Complications after Hypofractionated Radiation Therapy in Hepatocellular Carcinoma Matter? Cancer Res Treat. 2016;48:57482. doi: 10.4143/crt.2015.076. PubMed PMID: 26194367; PubMed Central PMCID: PMC4843719. 
24.Lin Y-T, Huang C-C, Chyau C-C, Chen K-C, Peng RY. Sixteen years post radiotherapy of nasopharyngeal carcinoma elicited multidysfunction along PTX and chronic kidney disease with microcytic anemia. BMC Urol. 2014;14:19.
25.Alavi M, Zal F, Zamani F, Kazemi M, Rasti M. Evaluation of a Number of Blood Biochemical Markers after Radioiodine Therapy in Papillary Thyroid Cancer Patients. Middle East J Cancer. 2017;8:77-82. 